
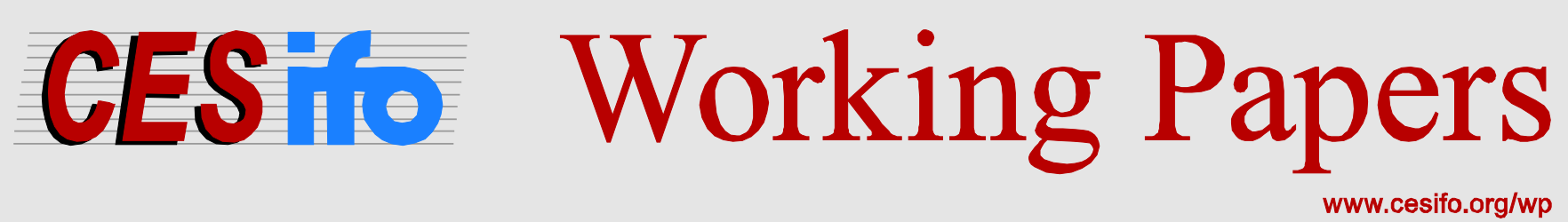

\title{
Beyond Non-Satiation: Needs and Requirements
}

\author{
Anna Pettini \\ CESIFO WORKING PAPER NO. 5110 \\ CATEgORY 12: EMPIRICAL AND THEORETICAL METHODS \\ DECEMBER 2014
}

An electronic version of the paper may be downloaded

- from the SSRN website:

- from the RePEc website:

- from the CESifo website:

wWw.SSRN.com

www.RePEc.org

www.CESifo-group.org/wp

\section{CESifo}




\title{
Beyond Non-Satiation: Needs and Requirements
}

\begin{abstract}
The hypothesis of non-satiation of rational choice theory is very seldom posed under scrutiny, maybe because it is taken as an anthropologic reality. Looking closer to that, we discover that it is taken for granted only in economic theory, and that it has become a reality as a result of a cultural process. This paper makes a brief story of this axiom, and looks at how it recently shifted into a modification of the original concept of adaptation. Using theoretical research in psychology, we find out that non-satiation is indeed not a natural feature of human beings, but a challenge to their happiness and a potentially pathological sign. The distinction between needs and requirements provides a new and solid ground on which we can discuss the quality of human needs, which is, according to Keynes, a key concept to define what the 'economic problem' is.
\end{abstract}

JEL-Code: D010, D110, D690, I310, I390.

Keywords: non-satiation, needs, requirements, happiness, choice, adaptation, economic problem.

\author{
Anna Pettini \\ Department of Economics and Management (DISEI) \\ School of Political Sciences \\ University of Florence \\ via delle Pandette 21 \\ Italy-50123 Florence \\ pettini@unifi.it
}

I am grateful to Claudio Gnesutta, Ernesto Longobardi, Vincenzo Patrizii and Andrea Ventura for their suggestions and comments. Usual disclaimers apply. 


\section{Introduction}

The hypothesis of non-satiation of neoclassical economic theory is definitely the least discussed axiom, in spite of the fact that it is crucial to ensure major results, spanning from the definition of optimal choice to the existence of the competitive equilibrium. Admittedly, among the axioms of consumer choice, non-satiation seems to have a different status, since it appears to be more an anthropologic trait than a perfect rationality requisite. The putative anthropological feature of nonsatiation, on the other hand, was proved not to be neutral in many respects, as it can cause problems on the ground of individual lives, social cohesion, and environment. ${ }^{2}$

In a recent book, Robert and Edward Skidelsky (2011) claim that insatiability is connate to humans, in spite of the fact that what is necessary to have a comfortable and good life is indeed upper bounded. On the other hand, they argue, the great part of needs are psychologically driven and this is the reason why they get unbounded both quantitatively and qualitatively. The only solution to insatiability, according to them, is the ability to say that 'enough is enough', by the means of a moral statement, namely to understand that insatiability drives lives far from being good lives.

Joseph Stiglitz (2010) drives the reasoning a bit further. He makes two major points. First, while insatiability is (apparently) a matter of preferences, it generates a problem of consistency of choice: for example, people say that care about their families, and that they work for their family, but they often work so hard that family life is destroyed (the means destroy the ends they seek). Second, he points out that consumerism is a cultural phenomenon, since "the economic system has created an insatiable sets of wants" (Stiglitz, 2010, p.63).

This paper makes a short story of the hypothesis of non-satiation. We observe that non-satiation is considered as a natural human characteristic only by economic theory, while psychology treats it as a pathological trait. Theoretical research in psychology provides a simple but not trivial key to discuss the nature of human needs: the difference between needs and requirements is an extraordinary tool to discuss non-satiation, and to deepen the research on the happiness paradox.

\footnotetext{
${ }^{2}$ For an overview on the negative drawbacks of non-satiation, see Bartolini 2010. To look closer at the effects of insatiability on (i) individual lives, (ii) society, and (iii) environment see: (i) Kasser (2002); (ii) Hirsh, F. (1976), Polanyi, K. (1968); (iii) Johan Rockström et al. (September 2009), Nature.
} 
This paper is structured as follows. Section 2 examines to what extent needs and desires can be considered as synonymous and how this distinction affects the research in happiness economics. Section 3 shortly describes how non-satiation of needs springs specifically in economic theory, while section 4 illustrates how, within the research in psychology applied to economics, nonsatiation shifts into the theory of adaptation. Theoretical psychology, on the other hand, points out that non-satiation is pathological (section 5). In section 6 we use the original theory of an Italian psychiatrist to show why non-satiation cannot be considered a natural feature of human beings, and why to make this point as clear as possible is today as crucial as ever. The last section summarizes. A last remark can result useful to what follows. Non-satiation should not be confused with the ordinary and purely reasonable thought that having a little more could help in having an easier life, at least when the budget constraint is effectively binding. Non-satiation means and implies that, whatever the material goods and the money we have, we will ever be less happy than we would be if we had more: more goods, more money. Ever.

\section{Absolute needs and relative needs}

[..] Now it is true that the needs of human beings may seem to be insatiable. But they fall into two classes --those needs which are absolute in the sense that we feel them whatever the situation of our fellow human beings may be, and those which are relative in the sense that we feel them only if their satisfaction lifts us above, makes us feel superior to, our fellows. Needs of the second class, those which satisfy the desire for superiority, may indeed be insatiable; for the higher the general level, the higher still are they. But this is not so true of the absolute needs-a point may soon be reached, much sooner perhaps than we are all of us aware of, when these needs are satisfied in the sense that we prefer to devote our further energies to non-economic purposes. ${ }^{3}$

It was early 30's. John Maynard Keynes wrote a short essay where he suggested his view about the future path of development, in particular about the economic perspective in 100 years ahead. We are not 100 years ahead Keynes's words about the economic perspective yet, but a number of reasons make it interesting to discuss his essay. Recently, it inspired three volumes collecting the considerations of a good number of distinguished economists. They compare Keynes's prevision to the current economic situation and they essentially agree on a point: Keynes's prediction is wrong. Let us consider a small number of statements from the contributions on Keynes's essay: “..."it is

\footnotetext{
${ }^{3}$ J.M. Keynes, Economic Perspectives for our Grandchildren, Essays in Persuasion, 1931.
} 
[..] as fascinating for the hidden assumptions about the nature of man as it for the predictions clearly wrong - about the evolution of the economy"4; "this specific prediction struck me as so absurd that I was eager to see the details of how he defended it" ${ }^{\text {" }}$. Keynes's idea on the future of economic system is in general considered partly naive and partly wrong due to an aristocratic distance from reality: "[..] he failed to take into account the boundlessness of human desire." maybe because he was affected by a sort of "elite communism",

Contemporary economists address a great richness of comments and considerations to Keynes's essay. They choose to analyze different aspects but, in a way, we can highlight three points fairly common and widespread in their analyses: (i) there is no difference between needs and desires; ${ }^{8}$ (ii) desires are unbounded and not satiable; (iii) the definition of the economic problem comes from desires.

We can observe that point (iii) causes a shift in the definition of the economic problem with respect to Keynes's point of view. Keynes suggests that an economic problem exists until absolute needs have to be fulfilled. Today, according to the most widespread view, the economic problem exists until desires are not completely fulfilled. If desires are infinite, to overcome the economic problem is impossible by definition: there will be always a new desire to meet, which is equivalent to say that there will always be an economic problem to be solved.

To think that needs and desires are synonymous, as well as saying that the economic problem arises from desires is not a new idea, for sure it does not spring from comments to "Economic perspectives": neoclassical economic theory has been found on these ideas as it does not make the difference between human needs and human desires. Consequently, the axiom of non-satiation states that both are unbounded.

\footnotetext{
${ }^{4}$ J. Stiglitz, "Toward a general theory of consumerism: Reflections on Keynes's Economic possibilities for our grandchildren", in: Pecchi, Piga, 2012, p.41.

${ }_{6}^{5}$ Robert H. Frank, "Context is more important than Keynes realized”, in: Pecchi, Piga,2012, p.139

${ }^{6}$ Robert H. Frank, p.139.

${ }^{7}$ Jean Paul Fitoussi says that going beyond material goods is only of 'educated bourgeoisie', namely those who had the luck of benefiting from higher education, had had enough time and money to enjoy arts and music. Jean Paul Fitoussi, "The end of (economic) history", in: Pecchi,Piga, 2010, p. 158.

${ }^{8}$ Needs and desires are often treated as synonymous, though they refer to very different contexts. The distinction between them may seem to go further the realm of economic language but it should not, as the definition of needs is crucial to define the economic problem. We will go through the definition of needs in what follows, and we will not confuse the term with that of desires unless reporting the words of other authors. The definition of the term 'desire' comes from psychology and psychiatry, and it obviously has nothing to do with consumption activity. It is, properly, "the reaction to a human external stimulus, perceived with psychic sensibility [..]; it proposes the positivity of a human identity developed differently from that of the perceiver. Together with the reaction of investment of the Self, the desire is activated as an evolutionary tendency to enrich our own identity, taking the human content from the other, i.e. taking the human quality we have felt intuitively, as it is something we (unconsciously) discover to be deficient of. (G. Del Missier, Glossary in: "The medicine of the mind", Colamedici et al., 2011).
} 
The axiom of non-satiation is probably the least discussed hypothesis of the traditional economic theory. To the one hand, the set of hypothesis underlying rational choice theory has been deeply scanned and criticized, up to the unspoken agreement that it was indeed far from representing real choices, but nonetheless somehow useful as a reference benchmark. To the other hand, the nonsatiation hypothesis has been looked at as (fairly) acceptable. The alleged identity between needs and desires is probably the reason why economists use to look at non-satiation as an anthropological truth. The set of hypothesis of consumption theory is necessary to ensure that preferences and rational choice are consistent to each other; non-satiation is necessary to guarantee that a rational choice is also a maximizing choice.

Traditional economic theory deals with needs only by the way of preferences, and assuming nonsatiation, it implicitly assumes that needs are in turn insatiable. In other words, rational choice theory is the framework by which needs and desires are thought unlimited and undistinguishable from each other. If non-satiation is taken for granted, some consequences follow straightly.

First, we can fully understand point (iii) above: it is impossible to overcome the economic problem as it was defined by Keynes, i.e. the point where absolute needs are satisfied. Indeed, in a theoretical framework in which there is no difference between absolute needs and desires, the economic problem cannot be solved, since it is not defined over a finite set of absolute needs, but on an unlimited set of desires. This is equivalent to saying that economic growth is the only way to pursue the economic problem, which is in turn impossible to be 'solved' as needs and desires are not satiable.

If non-satiation is assumed, economists have indeed only to worry about growth. This is a point of view very well known and still widely accepted. Looking at economic growth as the only mean by which human needs can be satisfied, however, has so far been deeply challenged by happiness economics, the premise of which can be well summarized by the words of two epidemiologists:

\section{[..] It is a remarkable paradox that, at the pinnacle of human material} and technical achievements, we find ourselves anxiety-ridden, prone to depression, worried about how others see us, unsure of our friendships, driven to consume and with little or no community life. Lacking the relaxed social contact and emotional satisfaction we all need, we seek comfort in over-eating, obsessive shopping and spending, or become prey to excessive alcohol, psychoactive medicines and illegal drugs.

How is it that we have created so much mental and emotional suffering? Despite levels of wealth and comfort unprecedented in human history. Often what we feel is missing is little more than time enjoying the company of friends, yet even that can seem beyond us. We talk as if our lives were a constant battle for psychological 
survival, struggling against stress and emotional exhaustion, but the truth is that the luxury and extravagance of our lives is so great that it threatens the planet. $^{9}$

Is non-satiation really a natural feature of human beings? If this is the case, a development model based on quantitative growth is unavoidable, and the negative drawbacks of it, those arising on the ground of individual and social happiness as well as on the natural environment, have to be faced separately.

If, on the other hand, non-satiation is not the natural attitude of human beings towards their own needs, but it is a cultural construction as Stiglitz suggests, this would mean that quantitative growth is no more the main goal of our economic systems. In this case, Keynes's words give us a hint to rethink what economics is nowadays aimed at.

\section{Needs become non satiable in economic theory}

When we talk about human needs, we face an issue closer to psychology, anthropology and sociology than to economics. Nonetheless, the theory of choice, as well as the theory of growth and development, are heavily founded on the interpretation of needs. This is the reason why, as economists, we cannot avoid dealing with it.

Human needs play a crucial role in quite a number of disciplines but, surprisingly enough, they are not frequently treated and, more importantly, there is no uniformity in the way they are named, and classified within each discipline and across them.

The concept of need is admittedly somehow ambiguous since humans are at the same time natural beings and social beings. The definition of human needs may be essentialist - needs cause individual and social behavior - or conventional if we think that what is and is not to be owned is established by society, so that individual behavior generates from it ${ }^{10}$.

While industrial capitalism was developing, classic economists used to look at human needs as the engine of economic activity. Adam Smith thought they are implicitly expressed in voluntary exchanges, David Ricardo moved a step forward saying that they have also a social component ${ }^{11}$, which become clear in Marx's subsistence-wage definition.

\footnotetext{
${ }^{9}$ Wilkinson, Pickett, 2010, pg.3.

${ }^{10}$ Peter Townsend, Poverty in the United Kingdom: A survey of household resources and standards of living, Berkeley, California, 1979, p.413.

${ }^{11}$ Subsistence level is to be defined not only in terms of what is necessary to survive, but also in terms of what is needed to have what is socially required.
} 
It is within early work in marginal analysis that we find the groundwork for the non-satiation hypothesis. Needs are hierarchically ordered, so that each time one of them is satisfied, a new one comes out, i.e. every single need has to be satiable. At the same time, global satiation is made impossible by the principle by which a new need always comes out.

Neoclassical theory makes this point even more explicit since utility subsumes needs, which, in turn, disappear behind preferences. The hypothesis of decreasing marginal utility allows for local satiation, while global satiation is prevented by non-satiation hypothesis itself, necessary to prove Walras's law. Traditional economic theory does not deal directly with needs, since it limits its attention to preferences, in a particularly emphatic way when revealed preferences assumption is added. According to revealed preferences approach, there is no difference between consumption choices and individual welfare, as the former reveals the latter, namely the correspondence between individual needs and welfare. Let's look closer at this sentence. It could apparently look to be the same idea about needs that we find in Smith, namely that needs are revealed by exchange and consumption choices, while the difference between the two approach is profound. In Smith' view choices reflects individual needs as an observation of reality. The revealed preferences approach is valid if non-satiation holds; the former is an empirical statement, the latter is a theoretical one, and it interprets every choice as a rational and maximizing choice. The former can be followed by the analysis of needs underlying the choice. The latter makes it impossible and useless to distinguish natural from social needs, because they are hidden behind individual preferences, which in turn cannot be known. It is worthwhile to underline that neoclassical economics assumes that individual behavior is rational, and that preferences are the bridge between choice and the maximization objective. A choice can reveal the individual objective if and only if preferences guarantee the consistency between the objective and the choice, namely if non-satiation holds.

Rational choice theory, as well as revealed preference theory, has long been discussed: theorists have extensively looked at the implications of each hypothesis on general results; empirical studies have long collected evidence in contrast with perfect rational choices. These discrepancies have been explained from a subjective perspective (there are systematic exceptions to personal rationality) ${ }^{12}$ as well as from an objective point of view (e.g. information is not perfect).

What do we have in contemporary economic literature? We find both models that treat private rationality as if it was never been discussed so far, as well as studies which move apart from it, and focus on single parts aimed at the foundation of a new general model. For the time being, no alternative is available, at least in the form of a general and widely accepted framework. The long

\footnotetext{
${ }^{12}$ The work of Daniel Kahneman has extensively and profoundly developed the research in this direction.
} 
and deep economic crisis of the last years, joined to environmental and distributional issues, have called economists to an urgent and profound debate about the foundations of economics, but the non-satiation hypothesis seems not to be part of it.

\section{The long lasting life of the non-satiation hypothesis}

The reason why the non-satiation hypothesis (hereafter NSH) has had little attention is probably that it is considered an anthropologic and even a self-evident truth, more than a rationality feature. There is a further difference between the destiny of NSH and that of the other axioms of consumer choice. The latter have somehow been left to the attention of EEG theorists or to the intersection ground of economics and psychology, while the former is now living a second life in the happiness economics literature, through the theory of adaptation, origined by Helson (1964). Many theorists explain the happiness paradox (namely the break of the causal link between the increase of richness and the increase of happiness), by accepting the idea that people adapt to what they have and this is the reason why they always want more, so that the increases in their happiness are only temporary.

Taken by their face value, the NSH and the adaptation hypothesis seem to be different. The former is an axiom; it states that utility is an increasing function of quantities, and it is defined in the 'utility space'. The latter is an explanation of why happiness does not grow as the quantity of goods grows, or why the increasing in happiness does not last, and it belongs to the 'space of happiness'. If we look at the two hypothesis a bit closer, on the other hand, we can observe that they mirror each other, as both imply that whatever the solution found by a chooser, there is always another solution, which would make her/him more satisfied, or happier. NSH implies that "more is always better", adaptation that "it is never enough".

Non-satiation becomes adaptation in the contributions of psychology applied to economic behavior, where a consistent number of recent studies aims at interpreting consumerism. They usually do not treat the issue of needs in itself, but they look at the reasons why insatiability arises. Most frequently, the attitude to non-satiation is explained by different forms of the so called "tapis rouland effect" (Biswanger 2006).

The first is the positional treadmill, according to which people compare their situation with that of the others, particularly with respect to wealth, and long for having more than the others. Some very expensive goods play this role since they signal the high level of wealth of those who can afford 
them. ${ }^{13}$ However, the position gained is continuously challenged by the fact that expensive goods quickly become 'old' and affordable by a higher number of people, and this is the mechanism by which the treadmill triggers.

The second is the hedonic tapis rouland, which focuses on the temporary effect given by goods to individual happiness. Consumerism springs because people try to gain happiness by what they buy, they soon adapt to what they have, so that they do not succeed in getting the hoped improvement.

There are then the multi-option and timesaving treadmills, proposed by Matthias Binswanger.

According to this approach, choice is made more complex by the increased number of options similar to each other. With a great number of varieties of the same good, those who have to choose one out of many options perceive to have less rather than more freedom of choice, since they can always think they have done the wrong choice (or that they have not done the best possible choice). This way, every decision may be somehow not final, leaving the person to the temptation to buy something else, up to get to consumerism.

The psychologist Barry Schwarts first introduced the multiple-option tapis-rouland. He developed the "satisfying behavior" idea, previously proposed by Herbert Simon. He claims that consumers are divided into two groups: maximizers and satisficers. A maximizer is a person who needs to be assured that every purchase or decision he or she does, was the best possible decision. A maximizer can be certain of his or her choice only when he or she considers all the possible alternatives. This creates a psychologically disheartening feeling, which can become even more serious as the number of options increases. The alternative to be a maximizer, is to be a satisficer. A satisficer has criteria and standards, but he is able to be happy with the choice done and not worried about the possibility that there might be a better choice.

Schwarts shows how differently these two groups of consumers react to the increasing number of choices available: while satisficers are not affected by it, maximizers become more anxious and worse off. Following the line traced by Schwarts, in other words, non-satiation is not of everybody, but only to those who fall in the "choice trap".

Up to this point, we have seen that psychology applied to economics, to the one hand, has depowered the rational approach to consumption by showing how the axiomatic approach does not describe real choices; to the other hand, it interprets non-satiation as a matter of fact, and somehow gives it a second life by merging it to adaptation.

\footnotetext{
${ }^{13}$ The use of goods to signal its own status is known in economic theory from late 1800: from Veblen's luxury goods, to oligarchic goods defined by Harrod and positional goods of Hirsh.
} 
Since non-satiation is the crucial assumption to step from rationality to maximizing behavior, we should be tempted to think that the homo oeconomicous anthropology somehow holds in reality: human beings have maybe limited rationality but, on average, they do live to have higher and higher quantities of commodities. Is it true? If it was, the happiness paradox had no chance to be solved.

\section{Non-satiation is not a natural human feature}

Keynes' distinction between absolute and relative needs is part of a long lasting moral and anthropological research, which goes from Greek to contemporary philosophy, and involves also every social science. Sociology is mainly interested in the needs of social organisms, like organization, stability and order. Nonetheless, it is sociology that yields a variety of dichotomies where needs are classified in primary and secondary needs, essential and not essential needs, avoidable and unavoidable, real and fictitious, and between needs acknowledged and not, up to the distinction between unconscious and conscious needs. In general, the first term of each dichotomy is considered as a need not conscious, while the second term of each dichotomy correspond to the class of conscious needs.

Social sciences use the category of social and individual needs but, in general, they get the definition from the work of psychologists.

In the last 30s of the $20^{\text {th }}$ century, Henry Murray (1938) worked on the difference between primary (somatogenic) and secondary (psychogenic) needs. Abraham Maslow (1954) stated that the greatest achievement and ultimate goal of human beings is self-actualization, which can be achieved if and only if a certain number of most fundamental needs is already achieved. Needs are hierarchically ordered from physiological to self-actualization, through safety, belonging, and esteem needs. He thought that basic needs are identical for number and kind for each person; while intermediate needs, (he calls them 'desires') may vary in number and type from a person to another since they change over time and space.

Some decades later, research in psychology focuses on placing needs in a basic taxonomy. Unlike Maslow's approach, where physiological needs were positioned at the bottom of the pyramid, most researchers highlight the importance of psychological needs.

Edward L. Deci and Richard M. Ryan identify three main intrinsic needs as the necessary condition for self-determination. According to them, these needs are universal and innate and include the need for competence, autonomy and psychological relatedness. The authors claim that 
when one of these three fundamental needs is not satisfied, 'replacement' needs arise because people try to face the lack of most fundamental needs, as intrinsic motivations are, by searching in the wrong direction. This is the reason why some people give a lot of importance to richness, fame or other extrinsic objectives: as they are not able to pursue intrinsic goals like their own development, good interpersonal relationships or the well-being of the community they belong to, they search for extrinsic and 'untrue' purposes. In line of their research, we can state that extrinsic goals, at times signaled by consumerism, arise for a sense of internal insecurity caused by the missing achievement of intrinsic goals, which in turn induces people to search an external confirmation of their personal value. Nonetheless, the fulfillment of extrinsic goals can only be transitory, as they cannot ever be what people aim at achieving. In other words, needs may appear to be unbounded only insofar as extrinsically driven. From this point of view, non-satiation does not indicate a tendency to enhance individual well-being, because it is the result of a substitution process, which, by definition, cannot make a person better off.

This approach is connected with that of previous studies, in particular those of Harry Stack Sullivan (1953), one out the most famous theorists of interpersonal psychology. He associates needs to specific developmental epochs during childhood. In each 'epoch' a child has a set of peculiar needs that can be satisfied only within that temporal window. If needs, healthy at the time they arise, are not complied, they extend to adulthood and take the form of "out-of-time needs", which in turn cannot ever find gratification because they could have been met only at the time they arose.

Heinz Kohut (1971), again within the psychology of human development, stated that a number of needs spring in childhood and are functional to a healthy psychological progress. If they are fulfilled immediately and completely at the time they arise, they tend to disappear with age and become the ground of self-esteem. In the opposite case, where they are not met at the right time, they last in adulthood and, as in the case of Sullivan's "out-of-time needs", they will be later the reason behind a hopeless research of personal value through a system of a not finite 'false needs'.

Some other authors have tried to drive human needs to a basic core. Len Doyal and Ian Gough (1991), for example, suggested that there are only two basic and universal needs: health and selfesteem. They are evidently universal, as they have to be met in order to avoid a certain damage for the person who does not enjoy them, whatever the social or cultural context he or she lives in. The two authors identify eleven more universal and intermediate needs, through which the two basic needs can be met. Unlike the case of universal and basic needs, the way to accomplish intermediate needs may vary over time and across socio-cultural contexts. In other words, in the 
case suggested by Doyal and Gough, we find the same distinction between a finite set of universal needs and a not finite set of intermediate ones as in Maslow's case. Like for the authors cited above, pathological consequences can originate when universal needs are not met, but not when social needs are not.

\section{Beyond non-satiation}

So far, we have seen that psychology looks at non- satiation within a pathological framework and that this trait vanishes within psychology applied to economics, most probably because it does not enter the physiology of human needs, but it limits its attention to the description of behavior in economic decision making and tries to explain the reasons of unhappiness.

In order to develop our research on insatiability of needs, and try to understand whether it does or does not belong to human physiology, it is necessary to look deeper inside research in psychology. Italian research in psychiatry provides an innovative point of view. The Theory of Birth ${ }^{14}$ of Massimo Fagioli, an Italian psychiatrist and psychotherapist, gives us a framework, which is independent of any specific taxonomy of needs. Within the description of the physiological development of human mind, we find the distinction between needs and requirements, which turns out to be crucial to our research purpose, since it provides a decisive tool to claim that nonsatiation does not belong to the physiology of human beings.

Needs are connected to the aim of maintaining a status of our physical equilibrium and health. Needs must be satisfied by a correct conscious behavior and conscious, even rational, decisional processes: we all need to face material reality correctly in order to gain what is necessary to live, as well as to ensure material necessities to stay nourished, safe, healthy. In this respect, needs are measurable, observable, comparable with those of the others. If we wanted to itemize them, the list would not be invariant to time and space, but it nonetheless would be finite, since needs are finite,

\footnotetext{
${ }^{14}$ The Theory of Birth offers a completely new psychodynamic theory. It was formulated in 1970, and first published in 1971 (M. Fagioli, Death Instinct and Knowledge; $13^{\text {th }}$ edition: 2010; German edition: Todestrieb und Erkenntnis, Stroemfeld Verlag, 2011.) The theory has been deepened and developed in sixteen further books and in a great number of articles by the same author, and it has been applied in the research and works of a great number of psychiatrists, psychologists and psychotherapists.

About the Theory of Birth, for what concerns its status of scientific theory according to the modern epistemological criteria see: M. G. Gatti, et al., 2012, Functional maturation of neocortex: a base of viability, The Journal of Maternal-Fetal and Neonatal Medicine, 25(S(1)):101-103; M. Pettini, 2009, A rose for Fleming. Scientific theories of nature and of human reality, Il Sogno della Farfalla, 1, pp.5-28; D. Polese et al., The possibility of treating Schizophrenia through psychotherapy based on neuropsyche physiology of the human birth, WPA World Congress of Psychiatry, Madrid, 14-18 ${ }^{\text {th }}$ September, 2014; WPA 2014 Abstracts Book, Vol.5, p. 348.
} 
thought the necessity to satisfy them is repeated over time (nobody can ever say: I am definitely free from the need to eat!).

Requirements relate to individual Identity, they are unique and specific for each person. Requirements spring from the not-conscious mind, and they must be realized in order to guarantee our psychic health. They are not classifiable, measurable or comparable, since they arise from the unconscious reality, which is not measurable, classifiable, or comparable with that of the others. Unconscious mind is not impossible to be known, if considered under the light of the psychodynamic of the Theory of Birth, but it cannot be explored with direct observation as it is material reality. The fulfillment of requirements is possible on the ground of individual ability to perceive our specific internal reality, and to meet the demands coming from it. In a situation of psychic health, conscious and unconscious thoughts continuously interact: the psychic activity moves towards the realization of personal requirements, and this activity may at times take the form of observable choices. Nonetheless, it is important to underline that in no case requirements become classifiable, as they remain individual-specific and in continuous and unbounded evolution.

Though briefly summarized, the definition of needs and requirements, and the distinction between them, helps us claiming that non-satiation is not a natural feature of human beings. Let us see why. Needs are indefinitely repeated over time, but their repetition does not entail they are infinite nor that they are insatiable: if a person eats too much, obesity can occur; if a person sleeps too long, there can be a problem of depression, and so forth. Requirements are not numerable, but in no case, they can be thought as not satiable: although the realization of requirements may require the use of material instruments, it will never overlap with them since they are of a different nature.

We can claim that, for a physically and psychically healthy person, needs are finite and requirements are infinite, in the sense of being potentially unlimited. The requirements of being (e.g. a good mother, a good friend) and doing things (such as painting, writing, making a good work), are unlimited because their realization is new at any time. For example, a beautiful painting will not be enough to give the painter the feeling of being capable all his life long, he will be eager to do new paintings to express his developing internal reality; when we have a good interplay with somebody, this stimulates us to have new other good relationships, and so on.

In every human activity there is often both the satisfaction of a need and the realization of a requirement. For example, the food we eat is necessary to live, to prepare it is a requirement of creativity, self-care, generosity toward the others; having an income from work is a necessary mean to satisfy own needs, to work well is a requirement of ability, expression, membership. 
In every activity, consumption included, needs and requirements are fused in a behavior that is (should be) the synthesis between what we do and what we feel natural for an internal requirement of beauty, coherence, identity, and so forth. Both needs and requirements are crucial for the wellbeing of everybody, none of them can remain neglected. The ultimate and most distinguishing goal of human beings is to search the realization of requirements, but needs must be satisfied as a prerequisite of it (if surviving is the problem, there will be little space for requirements).

Non-satiation may come out when the synthesis described above does not succeed, namely when the natural and physiological equilibrium between physic and psychic dimensions is lost. In this case, the natural and unending research to realize own requirements might not be recognized and, being unmet, it can be replaced, or simulated, by the insatiability of consumption. The ground of needs may become hypertrophic when requirements are not properly felt and recognized or, alternatively, when they are confused with relative needs. This confusion cannot be made at least by a theoretical approach: trying to answer to non-material requirements with material reality leads people to dissatisfaction, in the best hypothesis, when not to unhappiness or patent mental pathologies, as well described by the studies on the happiness paradox.

\section{Concluding remarks}

From Keynes' point of view, absolute needs are finite while relative needs are not, and since the economic problem is linked to absolute needs, a possible freedom is prospected for the humankind. After a little more than eighty years, many economists shake the head at this perspective as they attach the economic problem to relative needs; they take for granted that they are insatiable so that there is no possible freedom from them, and no possible relief from the economic problem itself.

Keynes' formulation of human needs is not focused on non-satiation, as standard neoclassical theory is, where non-satiation springs as an anthropologic and obvious state of affairs. Theoretical psychology, on its side, interprets non-satiation as such as a pathological trait or as a source of malaise. From the point of view of economics, human needs are undifferentiated and infinite, from that of psychology they are classifiable and finite. If we adopt the distinction between needs and requirements, it becomes clear that only requirements are not finite and that this cannot in any case be confused with non-satiation since it means to confuse the ground of material reality with that of non-material one.

The Theory of adaptation deserves a further remark. It comes from psychology, in order to explain the ability of people to react to unpredictable events that change significantly their lives. When economics borrows suggestions from psychology, the phenomenon of adaptation becomes the key 
explanation of the paradox of happiness, namely it is suggested as an explanation of the break in the causal relationship between the rise of wealth and the rise of happiness. Adaptation, by the extension of its meaning, becomes a substantial synonymous of non-satiation, and loose any link with the psychopathology attached to consumerism. In other words, non-satiation becomes a natural feature of human beings only on the ground of psychology applied to economics, while for theoretical psychology it is not natural at all. The Theory of adaptation, to some extent, interprets the process on self-realization, as that we described in the previous paragraph, namely a continuous internal and unbounded process. If, on the other hand, adaptation is interpreted as and unbounded sequence of material necessities, a conceptual mistake occurs: human realization, immaterial as the mind where it lives, cannot be overlapped to consumption patterns.

There is something more. If the theory of adaptation is (in essence) the only explanation the happiness paradox, there is no solution to this, which can be only bypassed with an ethical exercise. If we adopt the key-ground of requirements, we can observe that happiness declines when, being needs properly met, requirements are not recognized and this causes what psychologists describe as the impossible attempt to achieve any realization by buying things, and what happiness economics defines 'negative endogenous growth'.

The ground of requirements, in addition, let us understand that the paradox of happiness is the sign of a human truth: human realization is to be searched on a ground that goes beyond material reality. This is true both for what people ask themselves and to what they search in the relationship with the others, which is the ground on which relative needs are defined.

These observations suggest a final defiance. On the consequences of the possibility to overcome the economic problem, Keynes wrote:

\section{"[...] To use the language of to-day, must we not expect a general "nervous breakdown?",15}

Maybe the nervous crisis he predicted has occurred, it is still going on, and it is to be ascribed exactly to the reason he anticipated: progresses of technology and science have caused an increase of labor productivity sufficient to decrease the individual time ok work. Instead of facing the possibilities and difficulties associated to this fact, those that Keynes himself predicted, an economic system based on the 'invention' and on the 'construction' of non-satiation has been built, as pointed out by Joseph Stiglitz. This way, one of the most important challenges that humanity has ever faced has been circumvented, maybe only postponed: the emancipation from needs, which means an increasing space to be devoted to the search of realization of requirements, is a new

\footnotetext{
${ }^{15}$ J.M. Keynes, Economic Perspectives for our Grandchildren, in: Essays in Persuasion, 1931.
} 
challenge in history of human beings. ${ }^{16}$ Happiness, or simply well-being of people cannot increase until they are forced to the ground of material reality. From an operative point of view, we can find many interesting answers in the research on new indexes of welfare. ${ }^{17}$ On the theoretical front, it is nowadays compulsory to go on enriching the research in economics with the knowledge on human beings - the most important element of economics - in order to build our economic systems on what is necessary to let them flourish, instead on what makes them sick.

\section{References}

Ahuvia, 2008, If money doesn't make us happy, why do we act as if it does?, Journal of economic psychology, vol. 29, pp. 491-507.

J. Allister Mc Gregor, L. Camfield, A. Woodcock, 2009, Needs, wants and goals: wellbeing, quality of life and public policy, Applied research in quality of life, vol. 4, pp. 135-154.

S. Bartolini, 2010, Manifesto per la felicità, Donzelli editore.

M. Binswanger, 2006, Why does income growth fail to make us happier? Searching for the treadmills behind the paradox of happiness, The Journal of Socio-Economics, 35, pp. 366-381.

D. Colamedici, A. Masini, G. Roccioletti, 2011, La medicina della mente, (The Medicine of the mind) L'asino d'oro edizioni.

E. L.Deci, R. M.Ryan, 1980, Self-determination theory: when mind mediates behavior, Journal of mind and behavior, vol. 1, pp. 33-43.

L. Doyal, I. Gough, 1991, A theory of human need, London, Mac Millan.

M. Fagioli, 2010 [1972] Istinto di morte e conoscenza, L'asino d'oro edizioni. (German edition: Todestrieb und Erkenntnis, Stroemfeld Verlag, 2011).

M. Fagioli, 2013 [1980] Bambino donna e trasformazione dell'uomo, L'asino d'oro edizioni.

\footnotetext{
${ }^{16}$ Obviously, this is true for people living in developed economies, where average income is sufficiently high. In countries where basic needs are not met by a considerable part of the population, it would be of no sense to discuss the ground of requirements, at least not before having faced the ground of needs: seeking the realization of requirements can be very difficult for somebody who has to spend every day finding something to eat. It is nonetheless important to give attention to the different and (absolutely) new stage of development of mature economies. The fact that the current economic crisis is pushing an increasing number of people to a situation where basic needs are challenged again, could also be read as a fault in interpreting the novelty of the stage of development in western countries.

${ }^{17}$ The Better Life Index is the latest index of this kind. It is designed to compare some of the key factors that contribute to well-being in OECD countries. 11 topics reflect what the OECD has identified as essential to well-being in terms of material living conditions (housing, income, jobs) and quality of life (community, education, environment, governance, health, life satisfaction, safety and work-life balance). http://www.oecdbetterlifeindex.org/.
} 
M. Fleurbaey, 2009, Beyond GDP: The quest for a Measure of Social Welfare, Journal of Economic Literature, vol. XLVIII, n.4, pp. 1029-1075.

H. Helson, 1964, Adaptation-level theory: an experimental and systematic approach to behavior, New York, Harper and Row.

F. Hirsh, 1976, Social Limits to Growth, Cambridge: Harvard University Press.

D. Kahneman, 2011, Thinking, Fast and Slow, Farrar, Straus \& Giroux.

T. Kasser, 2002, The High Price of Materialism, Mit Press, Cambridge (Ma).

J.M. Keynes, 1931, Essays in Persuasion, London: McMillan.

H. Kohut, 1971, The analysis of the self, New York, International Universities Press.

A. Maslow,1954, Motivation and Personality, NY: Harper.

A. Maslow, 1962, Toward a Psychology of Being, NY: Van Nostrand, 1962.

L. Pecchi, G. Piga, 2008, Revisiting Keynes. Economic Possibilities for our grandchildren, The MIT Press, Cambridge, MA; London, England.

K.Polanyi, 1968, The Great Transformation, Boston: Beacon.

J. Rockström, et al. A safe operating space for humanity, Nature 461, 472-475 (24 September 2009)

B. Schwartz, 2000, Self-determination: the tyranny of freedom, American psychologist, vol. 55, $\mathrm{n}^{\circ}$

1, pp. 79-88.

B. Schwartz, J. Monterosso, S. Lyubomirsky, K. White, D.R. Lehman, 2002, Maximizing versus satisficing: happiness is a matter of choice, Journal of personality and social psychology, vol. $83, \mathrm{n}^{\circ}$ 5, pp. 1178-1197.

B. Schwartz, 2004, The paradox of choice, New York, Harper Collins.

B. Schwartz, 2005, The paradox of Choice: Why More is Less, Ecco Press.

H. A. Simon, 1955, A behavioral model of rational choice, Quarterly journal of economics, vol. 59, pp. 99-118.

H. A. Simon, 1956, Rational choice and the structure of the environment, Psychological review, vol. 63, pp. 129-138.

H. A. Simon, 1957, Models of man, social and rational: mathematical essays on rational human behavior, New York, Wiley.

R. Skidelsky, E. Skidelsky, 2012, How much is enough: money and the good life, Other press, New York.

H. S Sullivan, 1953, The interpersonal theory of psychiatry, New York, Norton.

P. Townsend, 1979, Poverty in the United Kingdom: a survey of household resources and standards of living, Berkeley, California.

M. Vansteenkiste, R.M. Ryan, 2013, On psychological growth and vulnerability: basic psychological need satisfaction and need frustration as a unifying principle, Journal of psychotherapy integration, vol. 23, n 3 , pp. 263-280.

C.A. Viano (a cura di), 1990 Teorie Etiche Contemporanee, Bollati Boringhieri, Torino.

R. Wilkinson, K. Pickett, 2009, The spirit level. Why more equal societies almost always do better, Penguin Group, London. 